\title{
CRISIS, LEARNING AND POLICY CHANGE IN THE EUROPEAN UNION
}

\author{
Jonathan C. Kamkhaji and Claudio M. Radaelli \\ Accepted for Publication \\ Journal of European Public Policy vol.23, 2016
}

\begin{abstract}
What is the causal relationship between crisis, learning and change? How does causality works in the current responses to the sovereign debt crisis provided by the European Union? We question the conventional identification of the cause-and-effect relationship provided by theories of crisis management, integration and policy learning. Drawing on models of contingent learning developed within psychology and behavioural and evolutionary economics, we theorise that surprise produces behavioural change via a fast-paced associative cue-outcome mechanism and that policy learning follows change. We then run our exercise in causal identification through a plausibility probe. We show that our argument passes the plausibility probe. Our conclusions on cognition and situational effects on learning suggest a new research agenda, more sensitive to how individuals behave in the real world and more robust in its micro-foundations.
\end{abstract}

Key words

CONTINGENT LEARNING; CRISIS; MECHANISMS; POLICY CHANGE; POLICY LEARNING

Only a crisis-actual or perceived_produces real change. Milton Friedman

\section{Motivation, topic and arguments}

What is the relationship between crisis, learning and change? In the history of European integration, the presence of a major crisis has often been the necessary condition for nonincremental change (Schmitter 1970). The crisis of the Eurozone and the responses produced by the institutions of the European Union (EU) make this question central both for researchers and policy makers. Let us briefly unpack this complex relationship between crisis, learning and change starting from the first two elements - crisis and learning. In general terms, crisis conditions are thought to have the potential to accelerate policy learning (Stern 1997: 73; Deverell 2009: 180-181; Birkland 2004). But there are crisisspecific conditions for change and types of crisis that facilitate or hinder learning (Smith and Elliot 2007). Different conditions of crisis development and termination, for instance, define 
its progression through time (fast or slow-burning, cathartic or long shadow) and hence affect the likelihood of learning ('t Hart and Boin 2001). An important theme in this literature is the difference between learning across crises and learning within a crisis. Intracrisis situations are constrained by time pressure: within a crisis, there is not enough time to learn the right lessons. The upheavals of the Eurozone since 2009 fall in the category of intra-crisis rather than inter-crisis management (Deverell 2009).

Turning to the second component of the causal relationship - from learning to change theories of learning in public policy (May 1992; Bennett and Howlett 1992; recently Biegelbauer 2015) have long discussed the determinants and levels of policy change (Hall 1993). Although the exact nature of the causal relationship between learning and change is still debated, the combination of integration theory and theories of learning in public policy shows a possible pathway between crisis, learning and change. And the pathway follows a sequence that goes from the crisis as trigger for learning, provided that some scope conditions are met (Lefkofridi and Schmitter 2014), to policy learning as causal determinant of non-incremental change. As we shall explain below, if we combine the two segments of the causal relationship and address the scope conditions, we should conclude that change is hardly predictable in the Eurozone crisis. Nonetheless, this crisis has indubitably led to nonincremental change in the form of 'more integration', at least in the main domains of Economic and Monetary Union (EMU) (Ioannou et al. 2015). This motivates a new reflection on the causal mechanisms between crisis and learning, and between learning and change.

In this article we perform an exercise in causal identification: we put forth a novel approach to the cause-and-effect mechanisms in processes of crisis management, learning and change. We argue that crises can produce sudden change via fast-paced processes of cueoutcome associations; that change in turn triggers policy learning - thus reversing the causal mechanism; and finally, that feedback reinforces the mechanisms of learning and locks-in change. To achieve that, we draw on strands of economics and psychology that are based on how individuals behave. This gives us strong micro-foundations. In particular we build on contingent learning and human contingency learning $(\mathrm{HCL})$. We theorise learning and change on the basis of what we know about behaviour - the theories we draw upon are behaviour-oriented. Indeed, to add flesh to the bones of our approach to learning, we perform a plausibility probe, showing how our argument broadly matches evidence on the 
Eurozone crisis. In particular, we draw attention to three dimensions: low-cognition associative responses, contingency, and feedback. We then relate these dimensions and more broadly our findings to integration theories, showing that a critical conversation is possible and fruitful.

A caveat: the mechanism we described is called contingent learning, which is a fast, surprise-triggered understanding of how cue-outcome associations work. Contingent learning is not based on drawing inferences from experience and does not involve any change of priors. Surprise trumps priors. Thus, contingent learning is not policy learning the type of learning discussed by political scientists - no matter what type of policy learning we consider (Bennet and Howlett, 1992). Contingent learning is also different from 'adaptive learning' in political science (Levy 1994; May 1992: 336-337), where we talk about minimal policy re-design in response to contextual variations.. May (1992) even doubts that re-design is a manifestation of learning. To paraphrase Checkel (1998: 546), in the adaptive mode, actors run into a new context, "go "ouch", and then recalculate how, in the pressure of the structure, to achieve their interests'.

The approach we offer goes much further than policy adaptation. We argue that in episodes of intra-crisis management characterized by 'stress, uncertainty, time pressure and demands for rapid action' (Deverell 2009: 182) real-time change takes place through associative processes of contingent learning and that the nature of this behavioural change is larger than re-design. Change can be greater than incremental adaptations. In change-ordie situations we find accidental (policy) heroes. They produce significant change and only later they reflect on 'what have we done' and start drawing inferences from experience, thus entering the world of policy learning as defined by political scientists. Thanks to the explicit conceptualization of the mechanism of contingent learning we also go beyond the crisis management literature that refers to such phenomena as mere 'improvisation' (Deverell 2009: 181; Birkland 2009: 154) or 'do something' in the immediate aftermath of a critical focusing event (Birkland 2004: 342). We further argue that conventional policy learning does not disappear, but that it occurs in the post-decisional phase as feedback that anchors change. 
In the remainder of the article we proceed by first reasoning on the nature of the Euro crisis. Then, we specify our explanatory framework by identifying causality between crisis, change and learning. This leads us to perform a plausibility probe. Finally, as mentioned, we relate our findings to theories of policy learning, making suggestions for further research.

\section{A 'bad' crisis for the EU?}

The debate on the nature of the Eurozone crisis is still open, especially among integration theorists (Tosun et al. 2014; loannou et al. 2015). For Lefkofridi and Schmitter (2014) this phase of integration is not a 'good' cathartic crisis. Indeed, they observe the reverse of the scope conditions for the cathartic crisis to occur. An important Jepp 2015 special issue qualifies this observation by arguing that although there has not been a federal 'cathartic' leap, the EU has been able to respond with a number of governance innovations, at least in the domains of economic governance and EMU. In this section we consider the literature on integration and the study of crisis management.

With regard to the former, Lefkofridi and Schmitter (2014) shed light on causal variables that have hindered learning: (a) The crisis trigger was exogenous and most of the responses to this shock were completely outside the control of EU policy-makers; (b) The impact of the crisis has been uneven, with cumulative effects in terms of North-South cleavages that have hindered mutuality and solidarity among the Member States. If cleavages have cumulative effects, solidarity and trust are unlikely to lift the EU off its collective action problems; (c) Absence of epistemic communities operating under conditions of low politicization; (d) Lack of visionary leaders or a set of well-identifiable, entrepreneurial institutions that point clearly to the finalité politique - such as the 'federal' or federalising EU. On the institutional side, there is not much to expect in terms of well-identifiable entrepreneurship/leadership and focal points for the causal effects of ideas to occur (Garrett and Weingast 1993;

Niemann and loannou 2015). EU decision-making is characterised by poly-centrism (e.g., Economic and Finance Committee; Eurogroup, European Central Bank, the President of the Commission; the German Chancellor) without a clear constitutional mandate. This leads to a 'strongly fragmented governance structure' (Van Esch and Swinkels 2015: 1204) that affects 
negatively sense-making during crises, the compatibility of beliefs, and the presence and effectiveness of leadership.

Among the decision-makers, the most visible (yet weak) sign of vision is the necessity to rescue the Euro 'whatever it takes' (Rehn 2010; Draghi 2012). For the European Commission and the European Central Bank (ECB), but also for Germany, this position goes hand in hand with the protection of the European project. In fact, a failure of monetary integration would undermine the whole EU's construction, possibly leading to full-blown disintegration. Most of the recent innovations in fiscal monitoring/surveillance and structural reforms derive from this commitment (Schimmelfennig 2015), as well as it does the critical decision to renege on the no bail-out clause of EMU in 2010 and to implement first ad-hoc rescue packages for financially distressed Eurozone members and then to establish a permanent stability fund. These innovations took place, paradoxically, without an explicit quantum leap, not only in the ideational and discursive dimension of decision makers, but also in their sense of uncertainty, threat and urgency (Van Esch 2015; Van Esch and Swinkels 2015). ${ }^{1}$ The political debate on the necessity of a resilient Euro and further integration has led Merkel and Hollande and different EU leaders to talk about constitutional federalism in allusive, almost reluctant ways (Borriello and Crespy 2015: 515). In short, key decision makers within the EU polity were not able or willing to articulate a vision and ideational paradigm to support non-incremental change; yet, the latter took place (loannou et al. 2015) within a relatively short timeframe in the first months of 2010.

Along with these EU-specific stumbling features, further hindrances to crisis-driven policy learning and change are posed by the very nature of the Eurozone crisis. Here we need the literature on crisis management. As mentioned, there is a crucial difference between intercrisis management and intra-crisis decisions in terms of policy learning (Birkland 2009; Deverell 2009). Inter-crisis management allows time to learn lessons between a crisis and the next - although this does not mean that learning processes are necessarily smooth (Birkland 2004; Boin et al. 2009; Nohrstedt 2009; Stern 1997). Intra-crisis management

\footnotetext{
${ }^{1}$ During the first six months of the crisis (November 2009 to May 2010) Van Esch and Swinkels (2015: 1220) argue that, 'rather than delving into the roots of the crisis, leaders predominantly discussed possible resolutions and the role they and others must play in them'.
} 
occurs when a specific crisis is still on going. It focuses on halting the effects of a crisis (Moynhian 2009), when there is little precious time for sense-making.

The crisis management literature also helps us to identify the Eurozone crisis as longshadow, that is, a crisis characterized by fast speed of development and by gradual speed of termination ('t Hart and Boin 2001). We often hear that the crisis provides a window of opportunity for change (see the sophisticated version of the argument in Birkland 2004). But the appearance of learning strongly depends on the temporal, cognitive and substantive constraints that the crisis itself poses. And these constrains are magnified in case of intracrisis management of a long-shadow series of critical events. In these instances, as Moynhian (2009: 191) puts it, decision makers 'must engage in sense-making under limited time, dynamic conditions, and intense pressure, evaluating the nature and scope of a crisis and searching for an appropriate response [...] They cannot make vague recommendations of policy suggestions for a distant future, but must implement whatever changes they can immediately'.

To wrap things up then, the puzzle that motivates our project is what kind of learning mechanism may have been at work under these conditions where we would not normally expect learning and substantial policy change to occur.

\section{Theorising (and reversing) the relationship between policy learning and change}

To sum up our previous arguments, the EU faces an exogenous crisis without the institutional, entrepreneurial and epistemic leadership that in the past proved indispensable to generate quantum leaps. The EU actors' constellation is still characterized by multiple veto points and players and by fragmented governance, increasing the distributive costs of policy change. Then, the long shadow crises and their intra-crisis management pose a serious time-constraint to lesson-drawing.

This interpretation arises from a classic understanding of the relationship between policy learning and policy change in political science. To achieve change, actors must learn in the first place, that is, they have first to acquire, accumulate, process and exchange knowledge and then behaviour accordingly. One way or the other, they draw inferences from their 
experience and this impacts on behaviour. In short, learning is the cause of policy change (May 1992; Hall 1993). The textbook example applied to EU integration is the process that led to Maastricht. The road to monetary integration took more than twenty years to be paved. It involved instances of epistemic learning, decisive political entrepreneurship, and ideational convergence over time towards a new policy paradigm (McNamara 1998; Verdun 1999).

This inferential learning that generates change, anyway, is challenged by the findings of experiments in behavioural/evolutionary economics and psychology. Here we consider 'contingencies' in two ways, using human contingency learning $(\mathrm{HCL})$ and the behavioural approach to contingent learning.

At the outset, let us consider two distinct dimensions of learning. One dimension is cognitive. Learning is about an individual that, faced with exogenous changes, considers whether her preferences are still satisfied when the environment differs from the past. This individual deliberates whether to carry on with current behaviour, or choose something else. This involves cognition, or, bluntly, something that goes on inside the mind. The other dimension is situational: the connection between events and consequences (or, to put in $\mathrm{HCL}$ vocabulary, cues and outcomes) is not always the same. It depends on the characteristics of the situation. Hence the event $X$ leads to $Y$ or $Z$ depending on what the situational context is. $\mathrm{HCL}$ and the behavioural approach to contingent learning work on the two dimensions of learning. The former explores causality by investigating the dimension of cognition. The latter looks at causality from the perspective of the situation. They are portrayed in figure 1.

Figure 1 here

Starting with cognition, in policy learning theories (May 1992) we assume that an individual, when making predictions or choosing behaviour on the basis of her understanding of causeeffect relations, reasons inferentially on what has happened (a series of cue-outcome relations) and chooses to confirm the prediction/action or turn to another type of behaviour 
available in her repertoire. This explicit inference-based process, granted bounded rationality, takes place gradually and is resource-intensive. It requires the conscious deployment of inferential cognitive capacities and reflexivity. $\mathrm{HCL}$ raises the question: what is the role of surprise on predictions and actions? Surprise is a set of unexpected cueoutcome relations - decision-makers are typically confronting these relations during a crisis. Through the analysis of blocking effects ${ }^{2}, \mathrm{HCL}$ studies show that the likelihood of change and learning for individuals strongly depends upon this kind of new (and surprising) causal associations, but in a much less resource-intensive fashion with respect to that envisaged by standard learning theories. In particular, associative HCL models (Rescorla and Wagner 1972; Allan 1993; Shanks 1995) connect lack of prior experience on novel causal relations (in terms of unexpected and confounded cue-outcome relations) with associative learning. For $\mathrm{HCL}$ theorists, it is exactly the lack of experience about the relationship existing between a given stimulus and an outcome that generates what we would call surprise. This surprise about the causal relationship, in turn, triggers learning in associative form. Note that associative $\mathrm{HCL}$ '...is thought to be fast acting, automatic, and would require little cognitive resources to act' (Morís et al. 2014: 77-78).

This phenomenon fits experimental reality much better than a predicate whereby prior sets of beliefs and paradigms about causation inform reasoned inferential behavioural change. Strikingly, this kind of '...learning of sound patterns can occur even without conscious attention' (Bannard and Tommasello 2012, emphasis added). Mutatis mutandis, this mechanism of behavioural adaptation seems to be a more appropriate depiction of the learning processes occurring during crises rather than the classic take on cognition in policy learning models. We can elaborate on this and argue that the findings of $\mathrm{HCL}$ suggest that resilient beliefs systems may not be a major hindrance to change - and learning. Surprise may trump priors via self-reinforcing mechanisms of association between new stimuli and outcomes.

\footnotetext{
${ }^{2}$ Put simply, blocking in HCL experiments refers to difficulty in learning on cue-outcome relations when a specific cue is paired with an outcome in a single stage and then in a successive compound stage of the experiment the same cue is paired with another one producing the same outcome of the single stage (Morís et al. 2014)
} 
These propositions do not come without qualifications, of course. Within $\mathrm{HCL}$, some have argued that contingency judgements and the actions that follow are not entirely driven by self-reinforcing, sometimes unconscious and automatic, associative mechanisms. For some (Cheng and Novick 1990; Cheng and Holyoak 1995), it is iterated statistical evidence and inference that reshapes responses to new cue-outcome relations. Thus, the discovery of new causal links between behaviour and consequences can also be led by inference rather than surprise-driven association (Allan 1993; De Houwer and Beckers 2002).

Nevertheless, all HCL models support the argument that effective changes in the responses to different stimuli (i.e. contingency judgments or actions) can be learned and refined in a relatively short amount of time (i.e. after only several trials) and in broadly associative fashion. Moreover, the experiments indicate that when changes in response to new and unexpected stimuli (like those emerging during crises) take place, the key drivers of change have more to do with contextual association mechanisms and framing effects rather than with beliefs' updating and conventional inferential reasoning (conventional for us, political scientists). Associative HCL is also well suited to account for common biases in decisionmaking. Focusing specifically on crisis-driven decision making within groups, the most commonly theorized biases are attentional bias (Rerup 2009) and groupthink (Choi and Kim 1999). As for the rationale linking associative learning to attentional biases, 'a loud noise is usually expected to capture more attention than a quiet noise. Associability refers to the ease or speed with which a stimulus can be learned about. It is further assumed that all else being equal, learning will be faster (associability will be higher) for more salient stimuli. Thus, the relationship between a loud noise and shock will be learned faster than between a quite noise and shock' (Mitchell and Le Pelley 2010: 1). Attentional bias can be smoothly integrated within groupthink dynamics. The evaluation of the salience of a given stimulus is based on collective confirmation biases. The faster (associative) learning triggered by salient stimuli is then subject to bandwagon effect finally resulting in beliefs' convergence and 'group thought' associative responses to crises.

Thus, experimental findings demonstrate that the degree and nature of change is greater the bigger the surprise and salience of a stimulus are, or in other words, the more unexpected, confounded and relevant stimuli are. This, applied to collective decision making, tells us that a shocking crisis can allow for more and faster change than a smooth 
process whereby knowledge is accumulated and processed rationally/inferentially and change takes place upon lengthy reflection.

Enter the behavioural approach to contingent learning now. This allows us to explore the situational dimension of learning. Like in the previous case, we focus on the identification of causal relations. We do that by drawing on a strand of experimental findings reviewed among others by Tilman Slembeck (1998 and 1999). This economist has turned to experiments to explore how situational variables affect learning. The situational determinants of learning are both structural and interactive. Structural determinants refer to the complexity of the environment and/or complexity of tasks, the degree of interdependency among actors (often operationalized as number of players), and how much information is available about the environment, the resources and the actors. Interaction determinants involve uncertainty about the strategies and quality, quantity, content and timing of feedback.

The findings of this approach complement (and converge with) those of HCL. In situations characterized by high structural and strategic uncertainty, fragmented information and poor feedback, even relatively small modifications of the context can nudge decisions effectively, triggering contingent learning (Slembeck 1998 and 1999). This is at odds with conventional views - where uncertainty, poor information and the wrong feedback hinder the mechanisms of learning. But it is not at odds with experimental evidence.

The point is that learning in theory and learning in experiments diverge quite significantly. Theories of learning in social sciences are ad hoc: when they are tested in experimental settings they function exclusively under narrow ideal-typical assumptions. Experiments (for instance the so called 'three-doors-anomaly' - Friedman [1998] - and the 'endowment effect' pioneered by Daniel Kahneman and colleagues [1991]) have indeed demonstrated that even marginally relaxing the initial conditions of a given real-world situation can have dramatic impacts on the 'on-paper rational' expectations of learning theories. The point is that learning theories only work under narrow, often unrealistic assumptions that rarely match the empirical reality of decision making. These assumptions cannot cover all the potential contingent circumstances that can impact on learning outcomes in actual situations, even more so in the case of critical emergency-driven policy-making. Therefore 
we need to develop a framework where contingencies - and their relation with observable outcomes - are properly factored in.

Empirically, the contingent mechanism has potential to explain intra-crisis learning during the Eurozone crisis whereby we observe both single-loop learning and policy change. A similar causal mechanism is sketched in the crisis management literature but, as far are we are aware, it has not been explicitly conceptualized under a theoretical construct with sound micro-foundations. Thus Birkland (2009:154) rightly observes that in intra-crisis management actors 'do not have a great deal of time to be reflective and, instead, must often improvise to find good interim solutions to problems that were unanticipated, or to problems that cannot be ameliorated through standard operating procedures'. But he portrays this phenomenon as 'improvisation'. Contingent learning relates instead to behavioural change as a result of inescapable systemic pressures, contingencies and unexpected stimuli that call for an immediate response. This happens in the absence of proper cognitive inferential processing of the new information.

Contingent learning is not learning lessons from the crisis hence, but learning (via change) during the crisis. Paradoxically, the resulting behavioural change can resemble the effects of double-loop learning, but the emergence of new policy paradigms and cause-effect beliefs under contingent learning is not the fruit of reflexive lesson drawing (for which time and knowledge accumulation are critical). Rather, it arises out of associative responses to unprecedented stimuli whose persistence calls for immediate action. The cognitive process behind change is therefore contingent and associative (as opposed to reflexive and inferential). Importantly, it also allows for cognitive biases to be factored in the decisional process. Contingent learning leads to outcomes typical of double-loop learning, but without reflexivity.

These phenomena, although largely overlooked in the literature and treated as improvisation, deserve instead an explicit conceptualization because they are typical of crises: 'Both single- and double-loop learning presuppose cognitive reflection. But as prior research on the topic shows, and as this study reiterates, such critical and deeper reflection is not a conventional response to crises. Rather than engaging in reflective cognition and analytical investigations in response to crises, managers tend to resort to mechanic 
adaptation and reflex reactions in response to failures and external threats" (Deverell 2009: 185, emphasis added). According to the associative mechanism, in intra-crisis management sense-making (cognition) and implementation of appropriate responses (behaviour) are conflated in a single process.

Our discussion leads us to the following observable implications. Under conditions of extreme surprise and uncertainty, we would expect the contingent learning mechanism to trump priors and policy-makers to respond in fast-associative ways. Policy-makers choose the (right) course of action absent inferential policy learning - they do not need to understand the major cause-effect relations at work in a situation to react. Sense-making and behaviour are a single process, as we just said. We would expect these responses to be patterned by the cue-outcome dyads we described (see also below). Then we would expect inferential learning to take place after change, provided that feedback is sufficiently strong to anchor the lessons learned.

\section{From experiments to politics}

We established that the decisional process leading to behavioural change can take place before policy learning occurs. In our approach, inferential learning takes place ex-post, as a reflection grounded on feedback. Once change has occurred, feedback, inferential/probabilistic reasoning, and reflexivity step in and determine the sort of conventional learning theorized in political science. This leads us to the (apparently paradoxical) inversion of causality: policy learning follows change instead of determining it. The approach has indeed proved to be in line with the experimental results. Of course, experiments operate at the level of individuals (and sometimes animals) under controlled conditions. Real-world politics operates at the level of complex organizations with multiple actors and, in the EU, different levels of governance - not in labs.

We have so far theorized learning and made a plausibility argument for an alternative understanding of causality. Can we also present a plausibility probe, looking at evidence that seems in line with our theoretical expectations? Can we then draw on our findings to enter a conversation with recent scholarship in integration theory inspired by Neo-Functionalism 
(NF: Niemann and loannou 2015) and Liberal Inter-governmentalism (LI: Schimmelfennig 2015)?

The plausibility probe is an empirical device to test the plausibility of a novel theoretical mechanism. The aim is to prove that the mechanism is at least feasible - yet feasible does not mean probable. Plausibility probes are common in exploratory studies (Eckstein 1992; Levi 2008) when dealing with new theoretical claims. Such exploratory probe is a first step in a multi-stage research agenda. Practically, we focus on the observable implications of the theorised mechanism. The probe is not a fully-fledged theory-testing exercise that can discriminate between rival alternative mechanisms. When we criticize existing theories of integration, the aim is to draw on our theorised mechanism to fill in the gaps in NF and LI, knowing that different causal mechanism may well have been at work during different stages of this long crisis. For us, the crucial episodes referring to the observable implications of our theory occurred in 2010 - and feedback anchored the contingent learning later on. This is not, therefore, a claim that contingent learning explains the whole set of episodes of the crisis or played out in all the crises of the EU.

\section{Plausibility probe}

The dreadful situation of Greek public finances was publicly disclosed in early December 2009 when new Greek Prime Minister George Papandreou announced that Greece's budget deficit would have peaked up to the $12.7 \%$ of the GDP - more than twice the figure previously announced. The cue was hence represented by the disclosure of the actual deficit. The expected outcome of this cue, under normal circumstances, would have involved little more than peers' criticism toward the interested country and a slight worsening of its financing conditions on the private markets. ${ }^{3}$ The EU policy reaction to this

\footnotetext{
${ }^{3}$ To use an accessible example, consider Pavlov's experiment with dogs. In that, a cue consists in a conditioned stimulus (e.g. Pavlov ringing a bell). The outcome consists instead in an unconditioned stimulus (e.g. Pavlov feeding the dogs after having rang a bell). After several iterations of this cue/outcome dyad, dogs learn to associate the unconditioned stimulus (cue) to the conditioned stimulus (outcome), even when the latter is not presented. In fact, Pavlov dogs start salivating (reaction) when the bell is rang (cue), that is, before the food is actually provided (outcome). The learned reaction defaults when the known cue/outcome relationship is blocked or modified, eliciting hence a different reaction that is triggered by contingent learning rather than by conditioning. In the Greek case, the new dyad is a high budget deficit (cue) coupled with a risk of sovereign default - a totally new outcome in the light of the fact that in the first decade of EMU risk premia and interest rates were strongly unresponsive to Member States' budgetary stance.
} 
situation, then, would have followed the usual procedure: the issuing of an early warning, the enactment of an excessive deficit procedure and an adjustment path agreed with the Commission. In fact, the risk of a Greek default, back in February, March and April 2010 was looming, but not totally concrete. ${ }^{4}$ To use the contingent learning vocabulary, the cue took place (that is, the coming out of the Greek government) but not yet its unexpected outcome (that is, the concrete risk of a sovereign default). In this in-between phase, lacking the clear emergence of the outcome, the contingent reaction could not be triggered; hence Member States and EU institutions were sticking to their beliefs and preferences. They engaged in what we call, with hindsight, denial. ${ }^{5}$

The explosion of risk premia on Greek debt issues and the subsequent risk of a sovereign default due to external market discipline represented by all means an unexpected outcome that interrupted the well-known and expected cue/outcome dyad and led to a contingent response. ${ }^{6}$ This latter took the form of the establishment of a bailout fund (outside the acquis communitaire) and the enactment of a more integrated and strict regime for economic governance. The chosen policy solution (the reaction) was contingent in that it did not belong to a set of predefined recipes drawn from conventional sense-making and long terms preferences and beliefs. To renege on the no bail out clause of EMU and to create an external vehicle for the financial rescue of Member States strongly defied functional and

\footnotetext{
4 “At the beginning of 2010, Greece had little difficulty raising new debt. On 25 January it went to market looking to raise approximately €3-5bn and came home with €8bn, because it faced demand for its bonds worth roughly €25bn. The same thing happened in early March, when the Greek government looked for $€ 5 \mathrm{bn}$ and found bids for just under three times that amount. Finally, it happened again in April, shortly after the European Union held out the promise of conditional support. Greece came to the market looking for $€ 1.2 \mathrm{bn}$ in short-term credits, found close to $€ 8 \mathrm{bn}$ in offers, and went home with $€ 1.5 \mathrm{bn}$ instead. Nor was debt servicing the major problem. Although the Greek government complained loudly about the yields necessary to attract attention to these new issues, they were broadly comparable to much of the debt it was retiring and so would not create problems until well into the future as the stock of debt to be serviced continued to mount" (Jones 2010, p. 28). What precipitated the crisis was not new financing or servicing, but the flow of old debt into new bonds. Specifically, markets worried that the Greek government would have trouble refinancing. Just under $€ 8.1 \mathrm{bn}$ in bonds were to come due on 19 May 2010, with another $€ 400$ million maturing fewer than two weeks later. Both of these existing tranches of debt carried very high coupons (or fixed interest payments) of 6\%" (Jones 2010, pp. 28-29).

${ }^{5}$ 'Few of the standard criticisms of Europe's economic and monetary union expressed serious concern for this [default] prospect. Even the more extreme criticisms did not make it the focus of their attention' (Jones 2010: 23).

${ }^{6}$ In the first decade of EMU, in fact, the many deviations from the SGP rules were never punished by the markets. In other words, risk premia were largely unresponsive to deviations from the SGP ceilings and risks of sovereign defaults within the Eurozone never arose.
} 
incremental solutions as well as the long-term preferences of core EU Member States. This accounts, in our opinion, as a contingent reaction.

Although Greek economic fundamentals appeared immediately extremely weak, it took a while before the awareness of this weakness fully translated in the new, unexpected outcome, that is, the objective risk of a Greek sovereign default. Following Jones (2010: 2829), this took place only as late as in April/May 2010 and accounted as a broadly unexpected prospect. ${ }^{7}$ Only then the unanticipated cue/outcome dyad of the mechanism of contingent learning was complete (where the cue is Papandreou's announcement and the unforeseen outcome is the risk of a Greek sovereign default). Whereas in $\mathrm{HCL}$ experiments cue/outcome dyads are presented to subjects sequentially triggering their immediate responses, the transposition of such sequence into crisis-based decision making allows for a slightly longer timeframe (weeks and months rather than seconds) but still rapid in terms of political time.

Thus, drawing on the vocabulary of the mechanism of contingent learning, we can say: When the cue (distressed public finances) is paired with its unexpected outcome (the tangible risk of sovereign default), we find behavioural change, that is, a new and different reaction. This is exactly when the associative processes of contingent learning applies, swiftly leading to a non-incremental policy change (the refusal of the no bail-out clause). Note that, exactly as predicted by the contingent learning mechanism, this change occurs without any modification of beliefs. Indeed, Van Esch (2014 and 2015) documents ambiguity, a relative level of flexibility (most of all in secondary beliefs), and a modest degree of convergence in EU leaders' views during the crisis. Yet it appears clear that core beliefs were not fundamentally altered (Van Esch 2015). This is the proof, for us, that our mechanism is plausible.

The mechanism explains also how contingent factors leading to change can make up for the lack of grand visions. Even an ordinary leader, with short-term electoral horizon, will be forced into change if the context presents extraordinary pressure. We reason that when the

\footnotetext{
${ }^{7}$ 'Few of the standard criticisms of Europe's economic and monetary union expressed serious concern for this [default] prospect. Even the more extreme criticisms did not make it the focus of their attention' (Jones 2010: 23).
} 
very existence of integration and domestic state structures is questioned by an extremely challenging context, decision-makers learn in associative fashion about contingencies and choose non-incremental change that enables them to survive, even if their core preferences would suggest them to go for more limited change.

\section{Contingent learning and integration theories}

Let us now draw on the findings to open up a critical conversation with integration theories. Integration theories don't have the aim of explaining crises. Yet they offer the most important conceptual apparatus to make sense of the current stage of integration, characterized by an attempt to cope with a political and economic crisis.

For Niemann and loannou the Eurozone crisis is in part an endogenous effect of the asymmetries of the EMU architecture. The integrative steps devised to cope with possible disintegration were somehow functionally written in EMU. In particular, 'the developments towards deeper economic integration can be explained as steps taken in order to alleviate functional pressures arising from an incomplete architecture created at Maastricht' (Niemann and loannou 2015: 201). We broadly agree with this general explanation of the nature of the integrative reforms of EMU spawned by the crisis. Yet we debate it on the basis of two arguments: uncertainty and timing of the decision making. ${ }^{8}$ First, this NF understanding of crisis management overlooks the profound uncertainty about causal relationships and consequences of different courses of action within major crises triggered by unexpected events. For example, no functional tension arisen from EMU architecture was able to account for and allowed predicting the emergence of the so-called fiscalfinancial nexus. Indeed, if the monetary-fiscal asymmetry of EMU was predictable from a functional perspective (following Niemann and loannou), many other aspects of the crisis led the EU in uncharted territories (Jones 2010). Second, with regard to the time dimension: 'all these steps deepened to a remarkable degree European economic integration within a relatively very short period of time' (Niemann and loannou 2015: 200). And yet, for

\footnotetext{
8 'At the level of the EU it was difficult initially to deal with the immediate crises of the day, as individual member states were uncertain what steps had to be taken at that level, given the speed of the unfolding crisis the limited budget of the EU and the lack of response mechanisms catering to this kind of crisis' (Verdun 2015: 219). 'In terms of European integration, these achievements are remarkable, not only for their scale and scope but also the speed with which they were adopted and put into place' (loannou et al. 2015: 164).
} 
functional pressures to translate into political spillovers it is necessary that: '(national) élites come to perceive that problems of substantial interest cannot be effectively addressed at the domestic level. This should lead to a gradual learning process whereby élites shift their expectations, political activities and [...] even loyalties to a new European centre' (ibid. 198, emphasis added). The fast speed of crisis development does not allow us to make the case for a gradual learning process, thus muting political spillovers. ${ }^{9}$

This point is reinforced also by the observation of the discursive dimension. True, we can show that the functional discourse was dominant by 2012 (Niemann and Ioannou 2015: 204). But it is much harder to show such circumstance in 2010 , that is, when the crisis started to spread its unexpected cues and major pro-integration measures were swiftly laid down in a virtual vacuum - both in the discursive and strategic dimensions (the key events and statements of 2010 appear in Jones 2010; loannou et al. 2015; Schimmelfennig 2015; Tosun et al. 2014: 197-198). Thus, for us, the scenario of 2010, when key reforms were swiftly agreed on under objective existential threats for the Eurozone, was one of decisionmaking wherein political actors did not have the time to consciously engrain functional pressures in their discourses and action. Our findings concur with the NF logic if the latter assumes that the functional tensions are not known to the actors. These are the classic spillovers generated by institutions and the responses of markets, rather than being cultivated or acted upon by strategic actors.

Intense uncertainty is vividly depicted also by the LI account of the crisis (Schimmelfennig 2015). Nonetheless the process of preference formation amid the 2010 storm is the result of hindsight - not insight. In fact, as proved by Van Esch (2014) through comparative cognitive mapping, the key decision maker singled out by the LI approach, Chancellor Angela Merkel, held no specific beliefs about benefits/disadvantages of deeper integration before the unfolding of the sovereign debt crisis in late $2009 .{ }^{10}$ The events of spring $2010-$ as narrated by Schimmelfennig (2015: 181-183) - can be understood in terms of hard bargaining and brinkmanship, but this presupposes steadfast preference formation. Yet, the

\footnotetext{
${ }^{9}$ Moreover, the other typology of supranational spillovers (the "cultivated ones") postulates a visible entrepreneurship by EU institutions that was not observed empirically.

10 'Prior to the outbreak of the Euro-crisis, the Chancellor makes few references to European integration and hardly mentions European economic and monetary integration' (Van Esch 2014: 293-294).
} 
timeframe of critical events, plagued by systemic uncertainty and inconsistent exogenous pressures arising from the markets, did not allow actors to factor in their utility functions the dimensions of the crisis. LI allows for bounded rationality, but to generate explanatory leverage it must assume that preferences are connected to clear, ranked payoffs of alternative courses of action.

We do not contend that by 2012 (i.e. when major reforms were already been shaped and agreed upon) the mixed motives and distributive dimension underlying the reforms were identifiable, but we cast serious doubts that in 2010 this could be possible in the clear-cut terms postulated by LI. Again, the fast nature of crisis development, the uncertainty about unexpected causal relationships and the exogenous market pressures calling for immediate measures limit both NF reasoning on long-term functional pressures and LI claims on preference formation.

In particular, if it is true that exit costs were broadly felt like untenable by all the players (Schimmelfennig 2015: 181-182 and 186-188), it is hindsight that informs us about the distributive nature of the integrative steps decided, not contextual and contingent insight present in 2010. True, dramatic changes of positions of the German government in spring 2010 about the Greek bailout can indeed belong to the logic of a chicken game and to the resort to brinkmanship. Nonetheless, they can also be fruit of acute uncertainty about the outcomes of different courses of actions and adaptive, associative (in HCL terms) responses to the huge exogenous and unprecedented pressures of the markets. Schimmelfennig (2015: 182) himself acknowledges in part this by stating that 'in a situation rife with uncertainty, Merkel ultimately decided against taking the risk of Grexit. This debate shows that the preferences of Germany, a core actor, on Grexit, a core policy issue, were not unitary, fixed or internalized.

Our approach offers a more fine grained understanding of the mechanism that led first to the emergency measures of 2010 (driven by contingency more than by functional pressures or rational calculations) and then only afterwards to the sense-making process that followed them in 2011 and 2012 that reached its peak with the 'Four Presidents Report' (van Rompuy, 2012). The latter belongs to the ex-post feedback and reflexivity part of the 
mechanism of contingent learning. Feedback reinforced the choices taken under pressure of the crisis in the associative, low-cognition fashion postulated by contingent learning.

Functional pressures arising out of the EMU architecture (NF) and national preferences and intergovernmental bargaining dynamics (LI) played an important role. Yet, context and contingency are not weighted enough under these explanatory mechanisms. The initial, external trigger of the crisis generated policy puzzles which were not fully covered by the functional understanding of EMU deficiencies and that did not allow, in the short-run, the neat formation of national preferences. Multiple market pressures on EMU (impinging on private banks, sovereign debts, single member states' political and economic systems and supranational institutions) provided new unexpected cause-effect relations for the decision makers. Our key argument is that contingent learning stepped in exactly in this phase. At the critical juncture of the crisis (from December 2009 until late April/May 2010, when the Greek bail-out was approved and successive versions of financial stability facilities were established), the context of urgency and 'need to save the Euro' changed their causal beliefs and led to a series of integrative reforms driven by associative mechanisms. This (contingent) learning process occurred without canonical inferential thinking and without a deep understanding of the paradigm shift it implied. Thus, the Euro was saved by a process of contingent learning fuelled by contextual features of the decision making - a process that, in a way, happened accidentally. Only after these hallmark decisions were taken, reflexive learning, sense-making, and neat preference formation took place, not before.

Epistemic communities and visionary leaders are not a necessary condition for change in this a contingent learning world. We do not need politicians to anchor their beliefs to the enlightenment produced by epistemic actors. Simply, in contingent learning models politicians do not have to draw inferences from evidence and 'understand' the best course of action out of the crisis before they select the right course of action. Thus, this condition is no longer necessary - it is not necessary because in contingent learning causality is different from the cause-and-effect relations of classic political science learning.

The variable of surprise (unexpected cue-outcome relations) typical of HCL models is pertinent here. In emergency, most of all in intra-crisis management, decision-making is faster. The conventional, inferential conditions for learning via experience, alteration of 
preferences, and deliberation are absent or suspended. Accidental, unwilling heroes change behaviour in a short time-frame, under conditions of structural uncertainty (recall Slembeck's conditions). Change-or-die choice architectures nudge our accidental federalists. Bankers like Draghi go on stage and make extraordinary commitments to do 'whatever it takes' to save the Euro. Merkel may defy conventional political science wisdom about elections and short-term horizon: she may outrage her political opponents, foreign ministers and her own coalition partners. This is what she did by reneging on the no bail-out clause of EMU and agreeing on a EU-based rescue package for Greece in April 2010. That was the genesis of the changes in the EU policy on acute financial instability. After the first Greek bail-out, the European Commission was given extraordinary power to scrutinise the national budgets of the Member States, even to impose fines and (automatic) sanctions. The Stability Fund established slightly later on is federal in nature, since it overtly overcomes the no-bail out principle. Under the pressure of the markets and in a classic trial-and-error dynamics, the instruments within the toolkit of the ECB have been enlarged allowing for a relaxation of the commitment to stable inflation in favour of a sort of discretion conceded to the central bankers (Buti and Carnot 2012).

There is also a role for Slembeck's condition about feedback mechanisms that lock-in the effects of learning. Feedback re-organizes the beliefs of policy-makers, making them learn how to operate within the new circumstances that become the new taken-for-granted context. This finding opens a conversation with historical institutionalism. Further research should explore how our behavioural, contingent mechanisms relate to the macro-historical mechanisms and types of changes described by Mahoney and Thelen (2010).

To conclude: we have proved that our theorized causal sequence passes a plausibility probe and is conversant with integration theories, not that the EU is learning how to avoid the next crisis. Learning can still be dysfunctional in an inter-crisis context: the current responses to the Eurozone crisis may lead to the next crisis, as suggested by the 'failing forward mechanism' of Jones et al. (2015).

\section{Conclusions}


We have explored the cause-and-effect relationship between learning and change in novel ways, drawing lessons from psychology and strands of behavioural and evolutionary economics to formulate new arguments about how cognitive and situational variables affect change. Our mechanism explains short-term, fast-brushed decision making involving and leading to abrupt change. This mechanism exerts its influence over the longer term via feedback and reinforcement of contingent decision making. Our analysis contributes to theories of learning, social mechanisms, and crisis management in public policy, by providing a new angle and lenses to theorize cause-and-effect mechanisms. These lenses may look abstract, but they have been developed on the accurate observation of how individuals behave under experimental conditions. Thus, they start from how people behave in the real world, not how people behave in game-theoretical models. This is an element of strength when we suggest - as we do - to draw implications from these models for public policy analysis and theories of European integration.

It would be wrong to use the lessons of our exercise to make strong predictions. We argue that our mechanism was present in this crisis, but other crises of the EU, past and present (think of the refugees crisis) may have very different underlying learning mechanisms. However, we have carried out a plausibility probe to show how the learning mechanisms that exist in the models may support observations of real-world EU learning. We have examined the effect of surprise, feedback, and uncertainty in the current responses to the crisis. Integration theorists working on mechanisms (like Jones et al. 2015) may benefit from our analysis by incorporating our causal sequence of crisis-contingent learning-changefeedback and conventional policy learning into their wider explanatory accounts of integration. We have not challenged integration theories, but used our claims about learning to fill in the gaps in existing theories of integration. There are indeed opportunities to exploit by incorporating the study of human cognition into integration theories. Overall, our findings suggest that contingent learning passes the plausibility probe. But our exploration of learning is not about what the EU, or the federalists, or anyone else should do. It is above all a call for a new research agenda in the field of policy learning, to make this field more receptive to and interested in micro-foundations drawn from the study of human cognition. 


\section{Acknowledgements}

[Reviewers] [TALK at Uni... Feb 2016]

\section{References}

Allan, L.G. (1993) 'Human contingency learning: rule-based or associtative?', Psychological Bulletin 114(3): 435-448.

Bannard, C. and Tomasello, M. (2012) 'Can we dissociate contingency learning from social learning in word acquisition by 24-month-olds?', PLOS ONE 7(11): e49881.

Bechtel, M.M, Hainmueller, J. and Margalit Y. (2012) 'Sharing the pain: Explaining public opinion towards international financial bailouts?', MIT Political Paper: 2012-5.

Bennett, C.J. and Howlett, M. (1992) 'The lessons of learning: Reconciling theories of policy learning and policy change', Policy Sciences 25(3): 275-294.

Biegelbauer, P. (2015) 'How different forms of policy learning influence each other: case studies from Austrian innovation policy-making' Policy Studies early view.

Birkland, T.A. (2004) 'Learning and policy improvement after disaster', American Behavioral Scientist 48(3): 341-364.

Birkland, T.A. (2009) 'Disasters, lessons learned, and fantasy documents', Journal of Contingencies and Crisis Management 17(3): 146-156.

Boin, A.R, 't Hart, P. and McConnell, A. (2009) 'Crisis exploitation: political and policy impacts of framing contests', Journal of European Public Policy 16(1): 81-106.

Borriello, A. and Crespy, A. (2015) 'How to not speak the F-Word: Federalism in French and German discourse in the Eurocrisis', European Journal for Political Research 54(3): 502-524.

Buti, M. and Carnot, N. (2012) 'The EMU debt crisis: Early lessons and reforms', Journal of Common Market Studies 50(6): 899-911.

Checkel, J. (1998) 'The constructivist turn in international relations theory', World Politics 50(2): 324-48.

Cheng, P.W. and Novick, L.R. (1990) 'A probabilistic contrast model of causal induction', Journal of Personality and Social Psychology 58(4): 545-567.

Cheng, P.W. and Holyoak, K.J (1995) 'Complex adaptive systems as intuitive statisticians: Causality, contingency, and prediction', in H.L. Roitblat and J.A. Meyer (eds.), Comparative Approaches To Cognitive Science, Cambridge, MA: MIT Press, pp. 271-302.

Choi, J.N. and Kim, M.U. (1999) 'The organizational application of groupthink and its limitations in organizations', Journal of Applied Psychology 84(2): 297-306. 
De Houwer, J. and Beckers, T. (2002) 'A review of recent developments in research and theories on human contingency learning', Quarterly Journal of Experimental Psychology $55 b(4): 289-310$.

Deverell, E. (2009) 'Crises as learning triggers: Exploring a conceptual framework of crisisinduced learning', Journal of Contingencies and Crisis Management 17(3): 179-188.

Draghi, M. (2012) Verbatim of the Remarks made by Mario Draghi at the Global Investment Conference, London, 26 July, available at

http://www.ecb.europa.eu/press/key/date/2012/html/sp120726.en.html (last retrived 21 October 2015).

Eckstein, H. (1992) Regarding Politics: Essays on Political Theory, Stability, and Change. Berkeley: University of California Press.

Friedman, D. (1998) 'Monty Hall's three doors: Construction and deconstruction of a choice anomaly', American Economic Review 88(4): 933-946.

Garrett, G. and Weingast, B. (1993) 'Ideas, interests, and institutions: Constructing the European Community's internal market', in J. Goldstein and R. Keohane (eds.), Ideas and Foreign Policy, Ithaca, NY: Cornell University Press, pp. 173-206.

Hall, P.A. (1993) 'Policy paradigms, social learning, and the state: The case of economic policymaking in Britain', Comparative Politics 25(3): 275-296.

Ioannou, D., Leblond, P. and Niemann, A. (2015) 'European integration and the crisis: Practice and theory', Journal of European Public Policy 22(2): 155-176.

Jones, E. (2010) 'Merkel's folly', Survival 52(3): 21-38.

Jones, E., Kelemen, D. and Meunier, S. (2015) 'Failing forward? The Euro crisis and the incomplete nature of European integration' Comparative Political Studies, early view.

Kaarbo, J. and Beasley, R. K. (1999) 'A Practical Guide to the Comparative Case Study Method in Political Psychology', Political Psychology 20: 369-391.

Kahneman, D., Knetsch, J.L. and Thaler, R.H. (1991) 'Anomalies: The endowment effect, loss aversion, and status quo bias', Journal of Economic Perspectives 5(1): 193-206.

Lefkofridi, Z. and Schmitter P.C. (2014) 'A good or a bad crisis for the European Union?', in M.J. Rodrigues and E. Xiarchogiannopoulou (eds.), The Eurozone Crisis and the Transformation of EU Governance Internal and External Implications, Farnham, Surrey: Ashgate, pp: 11-28.

Levy, J.S. (2008) 'Case Studies: Types, Designs, and Logics of Inference', Conflict Management and Peace Science 25(1): 1-18. 
Majoney, J. and K. Thelen (2015) (Eds.) Explaining Institutional Change: Ambiguity, Agency, and Power, Cambridge: Cambridge University Press.

May, P.J. (1992) 'Policy Learning and Failure', Journal of Public Policy 12(4): 331-354.

McNamara K.R. (1998) The Currency of Ideas. Monetary Politics in the European Union, Ithaca: Cornell University Press.

Mitchell, C.J. and Le Pelley, M.E. (eds.) (2010) Attention and associative learning: From brain to behaviour, Oxford: Oxford University Press.

Morís, J., Cobos, P.L., Luque, D. and Lopez, F.J. (2014) 'Associative repetition priming as a measure of human contingency learning: evidence of forward and backward blocking', Journal of Experimental Psychology: General 143(1): 77-93.

Moynhian, D.P. (2009) 'From intercrisis to intracrisis learning', Journal of Contingencies and Crisis Management 17(3): 189-198.

Niemann, A. and loannou, D. (2015) 'European economic integration in times of crisis: A case of neofunctionalism?', Journal of European Public Policy 22(2): 196-218.

Nohrstedt, D. (2009) 'Do advocacy coalitions matter? Crisis and change in Swedish nuclear energy policy', Journal of Public Administration Research and Theory 20: 309-333.

Rehn, O. (2010) 'Foundations for sustainable growth and job creation: Safeguarding financial stability and reinforcing economic governance in Europe', European Parliament Plenary Session, Ref: SPEECH/10/246.

Rerup, C. (2009) 'Attentional triangulation: Learning from unexpected rare crises', Organization Science 20(5): 876-893.

Rescorla, R.A. and Wagner, A.R. (1972) 'A theory of Pavlovian conditioning: Variations in the effectiveness of reinforcement and nonreinforcement', in A.H. Black and W.F. Prokasy (eds.), Classical Conditioning II: Current Research and Theory, New York: Appleton, pp. 6499.

Shanks, D.R. (1995) The Psychology of Associative Learning, Cambridge: Cambridge University Press.

Schimmelfennig, F. (2015) 'Liberal intergovernmentalism and the euro area crisis', Journal of European Public Policy, 22(2): 177-195.

Schmitter, P. (1970) 'A revised theory of regional integration', International Organization 24: 836-868. 
Slembeck, T. (1998) 'A behavioral approach to learning in economics. Towards an economic theory of contingent learning', European Economic Association Congress, Berlin.

Slembeck, T. (1999) 'Learning in economics: Where do we stand? A behavioral view on learning in theory, practice and experiments', Discussion Paper No. 9907, Department of Economics, University of St. Gallen.

Smith, D. and Elliott D. (2007) 'Exploring the barriers to learning from crisis: Organizational learning and crisis', Management Learning 38: 519-538.

Stern, E. (1997) 'Crisis and learning: A conceptual balance sheet', Journal of Contingencies and Crisis Management 5: 69-86.

't Hart, P. and and Boin, A.R. (2001) 'Between crisis and normalcy: The long shadow of postcrisis politics', in U. Rosenthal, A.R. Boin and L.K. Comfort (eds.), Managing crises: Threats, dilemmas, opportunities, Springfield (ILL.): Charles C. Thomas Publisher, pp. 28-46.

Tosun, J., Wetzel A. and Zapryanova, G. (2014) 'The EU in crisis: Advancing the debate', Journal of European Integration 36(3): 195-211.

Van Esch, F.A.W.J. (2014) 'Exploring the Keynesian-Ordoliberal divide. Flexibility and convergence in French and German leaders' economic ideas during the Euro-crisis', Journal of Contemporary European Studies 22(3): 288-302.

Van Esch, F.A.W.J. and Swinkels, M. (2015) 'How Europe's political leaders made sense of the Euro crisis: The influence of pressure and personality', West European Politics 38(6): $1203-1225$.

Van Esch, F.A.W.J. (2014) 'A matter of personality? Stability and change in EU leaders' beliefs during the Euro crisis', in D. Alexander and J. Lewis (eds.) Making public policy decisions: Expertise, skills and experience, London: Routledge, pp. 53-72.

Van Rompuy, H. (2012) Towards a genuine economic and monetary union. Brussels, 5 December 2012 [Four Presidents' Report].

http://www.consilium.europa.eu/uedocs/cms_Data/docs/pressdata/en/ec/134069.pdf

Verdun, A. (1999) 'The role of the Delors committee in creating EMU: An epistemic community?' Journal of European Public Policy 6(2): 308-28.

Verdun, A. (2015) 'A historical institutionalist explanation of the EU's responses to the euro area financial crisis', Journal of European Public Policy 22(2): 219-237. 